\title{
Glucose-6-phosphate-dehydrogenase Deficiency as a Risk Factor for Pterygium
}

\author{
Enrico Peiretti, ${ }^{1,2}$ Antonella Mandas, ${ }^{2,3}$ Pierluigi Cocco, ${ }^{4}$ Claudia Norfo, ${ }^{4}$ Claudia Abete, ${ }^{4}$ \\ Fabrizio Angius, ${ }^{4}$ Alessandra Pani, ${ }^{4}$ Sarab Vascellari, ${ }^{4}$ Guido Del Fiacco, ${ }^{1}$ \\ Dolores Cannas, ${ }^{4}$ Giacomo Diaz, ${ }^{4}$ Sandra Dessì, ${ }^{3}$ and Maurizio Fossarello ${ }^{1}$
}

\begin{abstract}
Purpose. Glucose-6-phosphate dehydrogenase (G6PD) is an important site of metabolic control in the pentose phosphate pathway (PPP), providing reducing power (NADPH) and pentose phosphates. The purpose of this study was to investigate the possible involvement of G6PD deficiency (G6PD-) in the pathogenesis of pterygium.
\end{abstract}

Methods. Erythrocyte G6PD activity was evaluated in 123 pterygium patients and in 112 age-matched control patients. Enzyme activity, mRNA, rate of growth, green autofluorescence, response to oxidative stress, and cholesterol metabolism were determined in pterygium fibroblasts (PFs) and in normal conjunctival fibroblasts (NCFs) isolated from G6PD normal (NCFs + and PFs + ) and G6PD - (NCFs - and PFs-) patients.

Results. Higher prevalence of G6PD - was found in patients affected by primary pterygium than in control subjects, both men and women, suggesting that this enzymatic defect may be a predisposing factor for pterygium. G6PD activity was significantly lower in NCFs - than in NCFs + , but not in PFs - than in PFs +. In PFs -, G6PD mRNA levels were significantly higher than in PFs +. Growth-stimulated NCFs - grew at half the rate of NCFs+, although PFs - and PFs + grew at the same rate. Increased green autofluorescence and susceptibility to oxidative stress were observed in PFs ( $+/-)$ and in $\mathrm{NCFs}-$, but not in NCFs + . Moreover, ex vivo PFs $(+/-)$ accumulated more lipids than corresponding NCFs.

Conclusions. The results of this study, although restricted to a limited group of subjects (i.e., those of Sardinian ancestry), suggest that G6PD - not only does not protect against pterygium, but may even be considered a risk factor for the development of this disorder. (Invest Ophthalmol Vis Sci. 2010;51: 2928-2935) DOI:10.1167/iovs.09-4426

From the ${ }^{1}$ Department of Surgical Sciences and Odontoiatry, Eye Clinic, and the Departments of ${ }^{3}$ Internal Medical Sciences and ${ }^{4}$ Biomedical Sciences and Technologies, University of Cagliari, Cagliari, Italy.

${ }^{2}$ Contributed equally to the work and therefore should be considered equivalent authors.

Supported by grants from Regione Autonoma della Sardegna and Fondazione Banco di Sardegna.

Submitted for publication August 5, 2009; revised November 23 and December 20, 2009; accepted December 22, 2009.

Disclosure: E. Peiretti, None; A. Mandas, None; P. Cocco, None; C. Norfo, None; C. Abete, None; F. Angius, None; A. Pani, None; $\mathbf{S}$. Vascellari, None; G. Del Fiacco, None; D. Cannas, None; G. Diaz, None; S. Dessì, None; M. Fossarello, None

Corresponding author: Maurizio Fossarello, Clinica Oculistica, Dipartimento di Scienze Chirurgiche ed Odontoiatria, Università degli Studi di Cagliari, Ospedale San Giovanni di Dio, Via Ospedale 48, I09124 Cagliari, Italy; mfossarello@libero.it.
G lucose-6-phosphate dehydrogenase (G6PD), coded by a gene located on the long arm of the human X-chromosome, is the key cytosolic enzyme in the pentose phosphate pathway (PPP). ${ }^{1}$ There are two distinct phases in the pathway. The first is the oxidative phase, in which the co-enzyme nicotinamide adenine dinucleotide phosphate-reduced (NADPH) is generated, and the second is the nonoxidative synthesis of pentose (5-carbon) sugars. ${ }^{2}$ NADPH, by maintaining reduced levels of glutathione $(\mathrm{GSH})$, in both non-nucleated (i.e., red blood cells) and nucleated cells, plays a crucial role in the protection of cells from oxidant injury. ${ }^{3}$ It has been shown that G6PD is the only NADPH-producing enzyme that is rapidly activated in response to oxidative stress. ${ }^{4}$ Moreover, in nucleated cells NADPH is essential for fatty-acid and cholesterol biosynthesis. ${ }^{5}$ Pentoses, which are structural components of nucleic acids, have an important role in the control of cellular growth. ${ }^{6}$

G6PD deficiency (G6PD-) is a common enzymopathy affecting more than 400 million people worldwide ${ }^{7,8}$ and roughly 200,000 people ( $12 \%$ of the population) in Sardinia, Italy. ${ }^{8}$ Because G6PD - is an X-linked disorder, males may be affected or unaffected, because they are hemizygotic (XY). By contrast, as females have two $\mathrm{X}$ chromosomes, they are either homozygotes or heterozygotes. Therefore, G6PD- is more frequently observed in males, homozygotic females being extremely rare. The heterozygotic female has a mosaic cellular pattern, with two cell populations: one G6PD normal $(\mathrm{G} 6 \mathrm{PD}+)$ and the other G6PD - . Clinical manifestations are generally milder in females and depend on the degree of mosaicism. ${ }^{1}$

Nucleotide sequence analysis has shown that a $\mathrm{C}>\mathrm{T}$ transition in exon 6 , causing a Ser-Phe amino acid change at position 188 of the protein, is responsible for all forms of very severe G6PD deficiency in Sardinia and possibly in the Mediterranean area as a whole. ${ }^{8}$ In hemizygotic males, red blood cells show less than 5\% of normal G6PD activity. In bone marrow stem cells, however, enzyme synthesis is unimpaired; rather, enzyme stability is reduced. ${ }^{9,10}$ The recent discovery of the crystalline structure of $\mathrm{G} \mathrm{PD}{ }^{11}$ has provided insights into the mechanistic basis of this reduced stability. It has been suggested that the mutation causes a loss of the normal folding of the G6PD protein. These unfolded forms are susceptible to proteolytic degradation, and consequently the enzyme has a shorter half-life. In red blood cells this shorter-lived enzyme leads to a reduction in NADPH production and consequently in GSH levels, rendering these cells more vulnerable to oxidative damage and to a possible bemolytic crisis (i.e., favism). ${ }^{9}$ Actually, the distinctive phenotype of subjects with G6PD deficiency is hemolytic anemia, caused by exposure of red blood cells to oxidative agents. ${ }^{12}$ With the advancements in the field of G6PD research, it has become certain that this enzyme is an indispensable component of antioxidant defense; still, whether 
G6PD deficiency plays pathogenic roles in diseases other than hemolytic disorders remains to be clearly defined.

Besides being present in red blood cells, in fact, this innate defect affects all nucleated cells. ${ }^{13,14}$ Despite that, the consequences of having G6PD - nucleated cells have seldom been investigated, and in existing studies, conflicting conclusions have been drawn. ${ }^{15-19}$

Pterygium, a common ocular surface lesion, is a benign conjunctival growth. It is associated with and thought to be caused by reactive oxygen species (ROS) formation after exposure to ultraviolet (UV) light (e.g., sunlight), low humidity, and dust. ${ }^{20-22}$

Considering the role of G6PD in cellular growth and the proliferative nature of pterygium, the absence of G6PD may be expected to protect its development. On the other hand, consistent with the notion that G6PD - cells are more susceptible to oxidative stress, ${ }^{23}$ it could be argued that G6PDsubjects have a potentially increased chance of developing pterygium.

In an attempt to explain this apparent discrepancy, in the present study we evaluated the prevalence of G6PD deficiency in a Sardinian population with pterygium. We investigated G6PD activity and the growth rate of fibroblasts isolated from pterygium of G6PD + and G6PD - patients $(\mathrm{PF}+$ and $\mathrm{PF}-$, respectively) and compared them with fibroblasts isolated from normal conjunctiva of G6PD + and G6PD - subjects (NCF + and $\mathrm{NCF}-$, respectively) and G6PD mRNA levels in $\mathrm{PF}+$ and $\mathrm{PF}-$ subjects. In addition, since alterations of cholesterol metabolism, mainly cholesterol esters, have been found during the growth of PFs, ${ }^{24-26}$ we determined cholesterol metabolism in normal conjunctival fibroblasts and PFs, both G6PD - and G6PD+, either quiescent or growth stimulated.

\section{Materials ANd Methods}

\section{Study Group}

The study group consisted of 123 patients affected by primary pterygium (mean age $57.6 \pm 15.4$ years) admitted for pterygium surgery at the University Eye Clinic of Cagliari (Sardinia), between January 2005 and June 2009. Diagnosis of pterygium was based on clinical history and evaluation of signs and symptoms. All patients with pterygium had at least a 3-year history of a slow-growing lesion, with a corneal extension of at least $2 \mathrm{~mm}$, as measured with a caliper, from the limbus to the corneal vertex. One hundred twelve subjects (mean age, $59.4 \pm$ 10.8 years) admitted for cataract surgery were used as control subjects. Blood samples from cases and control subjects were collected for quantitative erythrocyte G6PD determination. Moreover, a second control group, represented by 8445 blood donors surveyed in the same period at the Hospital Transfusional Center of Cagliari, was considered for analysis of G6PD prevalence. Levels of erythrocyte G6PD activity ranging between 0 and $0.2 \mathrm{IU} / \mathrm{g}$ Hb were considered severely deficient; those ranging between 2 and $10 \mathrm{IU}$ were considered intermediate; and those higher than $10 \mathrm{IU}$ were considered G6PD normal. No subject in the blood donor control group had any inflammatory signs or symptoms. The research adhered to the tenets of the Declaration of Helsinki. Written informed consent was obtained from all the patients before blood and tissue were collected. This study and all the procedures, including biopsy of the conjunctiva during cataract surgery, were approved by the Ethics Committee of the University of Cagliari.

\section{Fibroblast Isolation}

For fibroblast isolation, we selected eight male patients (four erythrocyte G6PD + and four erythrocyte G6PD-) with primary pterygium (age range, 45-65 years; mean, $57.3 \pm 3.5$ years) and eight male patients (four erythrocyte G6PD + and four erythrocyte G6PD-) with normal conjunctiva (age range, 60-70 years; mean, $63.7 \pm 1.4$ years), who underwent cataract surgery at the University Eye Clinic of Cagli- ari. All tissue samples were obtained as previously described. ${ }^{24-26}$ In brief, at the time of surgery, both normal and pterygial specimens were excised from the nasal canthus with microforceps. As a rule, within 1 hour of excision, the samples were placed in sterile boxes containing a preservative solution (Eurocollins; Roche Biochemicals, Mannheim, Germany), and were transferred to the cell culture room. For fibroblast isolation, the tissues were dissected into three to four $1-\mathrm{mm}^{2}$ fragments. The fragments were placed in six-well plates for 2 hours. After 2 hours of cell adhesion, a few drops of Dulbecco's modified Eagle's medium (DMEM; Invitrogen-Gibco, Grand Island, NY) supplemented with $10 \%$ fetal bovine serum (FBS; Sigma-Aldrich, Munich, Germany), $100 \mathrm{U} / \mathrm{mL}$ penicillin/streptomycin (Sigma-Aldrich), and amphotericin B (Fungizone; Life Technologies, Gaithersburg, MD) were added to cover each fragment. The next day, the tissue fragments were covered with culture medium and placed in a humidified incubator $\left(37^{\circ} \mathrm{C}, 5 \% \mathrm{CO}_{2}\right)$. The medium was changed every 2 days. After 5 to 6 days, the fibroblasts began to proliferate from the fragment margin (halo of cells) and created a monolayer. The outgrowing cells were morphologically consistent with fibroblasts by their characteristic spindle shape. After 4 weeks, fibroblasts were purified by repeat trypsinization (trypsin/ EDTA, $0.05 \% / 0.02 \%$ ) and passaging to achieve a homogenous population of spindle cells. The purified cells were washed twice with sterile phosphate-buffered saline (PBS), centrifuged, seeded $\left(1 \times 10^{6}\right)$ into a $25-\mathrm{cm}^{2}$ culture flask, and grown to confluence. At this time, the cells were used for in vitro staining experiments or were transferred to cryopreservation medium at a suspension of $1 \times 10^{7}$ cells $/ \mathrm{mL}$. After swift freezing, the fibroblasts were placed in liquid nitrogen for longterm storage. When needed for the experiments, the cryopreserved cells were removed from the liquid nitrogen tank and cultured under the conditions described. All experiments were conducted in fibroblasts between passages 2 and 4 .

\section{Determination of Growth Rate}

For growth rate determination, cells were placed at a density of 40,000 cell $/ \mathrm{cm}^{2}$ in six-well plates and then were incubated for 24 hours in DMEM with $0.2 \% \mathrm{FCS}$, to synchronize the cells in a quiescent state. The quiescent fibroblasts were then diluted in complete growth medium containing $10 \%$ FCS and harvested at the indicated time points. The growth rate was assessed by counting the cells with a hemocytometer and by incorporating $\left[{ }^{3} \mathrm{H}\right]$ thymidine $(10 \mu \mathrm{Ci} / \mathrm{mL})$ into the DNA. In this experiment, $\left[{ }^{3} \mathrm{H}\right]$ thymidine was added 3 hours before the cells were harvested. Trypan blue uptake was used to determine cell viability.

\section{G6PD Activity Assay}

Venous blood from patients and control subjects was collected in EDTA for quantitation of G6PD activity, according to the Beutler method. ${ }^{27}$ Briefly, for determination of erythrocyte G6PD level, the cells were prepared by centrifuging whole blood at $2000 \mathrm{~g}$ for 10 minutes at $4^{\circ} \mathrm{C}$. Plasma and buffy coat were carefully removed, and red cells were hemolyzed with 4 volumes of cold, distilled water. G6PD activity was evaluated in hemolysates and the values expressed as nanomoles of NADPH formed per minute (IU) per gram $\mathrm{Hb}$. For determination of G6PD activity in fibroblasts, $10^{6}$ cells were homogenized with 9 volumes of $50 \mathrm{mM}$ Tris- $\mathrm{HCl}$ buffer $(\mathrm{pH}$ 7.5) containing $0.15 \mathrm{mM} \mathrm{KCl}$. G6PD activity was determined in fibroblast homogenates and expressed as nanomoles of NADPH (IU) formed per minute per $10^{6}$ fibroblasts.

\section{Determination of Intracellular Lipid}

Intracellular lipids were visualized by washing cultured fibroblasts with PBS and fixing them in $4 \%$ paraformaldehyde. The cells were then stained with the dyes oil red O (ORO; Sigma-Aldrich), Nile red, and filipin. ORO staining, specific for neutral lipids, was made in $60 \%$ isopropyl alcohol, followed by Mayer's hematoxylin counterstaining. ORO was observed in transmitted white light. Nile red (9-diethylamino5H-benzo $[\alpha]$ phenoxazine-5-one; Fluka, Buchs, SG, Switzerland) is a fluorescent dye that stains polar lipids (i.e., phospholipids) and neutral 
TABLE 1. Primer Sequences and Sizes of PCR Products

\begin{tabular}{|c|c|c|c|}
\hline Gene & PCR Primers & $\begin{array}{c}\text { PCR Protocol } \\
\text { (Number of Cycles) }\end{array}$ & $\begin{array}{r}\text { Size } \\
(\mathbf{b p})\end{array}$ \\
\hline G6PD & $\begin{array}{l}\text { 5' - CTGGAACCGCATCATCGTG - 3' } \\
5^{\prime}-\text { TTCTCATCACGGACGTCATCT - 3' }\end{array}$ & $94^{\circ} \mathrm{C} 50 \mathrm{~s} / 60^{\circ} 50 \mathrm{~s} / 68^{\circ} \mathrm{C} 90 \mathrm{~s}(25)$ & 916 \\
\hline$\beta$-actin & $\begin{array}{l}5^{\prime}-\text { AGGGGCCGGACTCGTCATACT - 3' } \\
5^{\prime} \text { - GGCGGCACCATGTACCCT - 3' }\end{array}$ & $95^{\circ} \mathrm{C} 30 \mathrm{~s} / 60^{\circ} \mathrm{C} 59 \mathrm{~s} / 72^{\circ} \mathrm{C} 45 \mathrm{~s}(20)$ & 202 \\
\hline
\end{tabular}

lipids (i.e., cholesterol ester and triglycerides) differentially. ${ }^{28}$ Polar lipids show a prevalent red emission, whereas neutral lipids show both a red and yellow emission. Red emission (referred to as Nile red [NR]-590) was observed with $540 \pm 12.5$ excitation and $590 \mathrm{LP}$ emission filters. Yellow emission (referred to as NR-535) was observed with $460 \pm 25$-nm excitation and $535 \pm 20$-nm emission filters. Filipin (Sigma-Aldrich) is a fluorescent dye that stains only free cholesterol. It was observed with $360 \pm 20$-nm excitation and $460 \pm 25$-nm emission filters. Filipin and Nile red emissions were completely separated by using the indicated filters, so that these fluorochromes could be used in combination. ${ }^{28}$ Cells growing in glass-bottomed dishes were observed with an inverted microscope (IX 71; Olympus, Tokyo, Japan), using a $20 \times / 0.7$ or $60 \times / 1.3$ planapochromatic objective (UPlanSApo series; Olympus) which provided a good alignment of different color emissions. Twelve bit-images were captured with a cooled CCD camera (Sensicam PCO, Kelheim, Germany). Nominal resolutions of images were 0.3 and $0.1 \mu \mathrm{m} /$ pixel with the $20 \times$ and $60 \times$ objectives, respectively. Quantitative image analysis was performed on computer (ImagePro Plus; Media Cybernetics, Silver Springs, MD).

\section{RT-PCR Analysis}

Expression levels of G6PD mRNAs were evaluated in PFs and in NCFs by semiquantitative, reverse transcription polymerase chain reaction (RT-PCR) with $\beta$-actin as the RNA control. RNA extractions were performed in approximately $10^{6}$ cells (Trizol; Invitrogen). The RNA concentration was measured spectrophotometrically at $260 \mathrm{~nm}$, and the 260:280-nm ratio was evaluated to check for protein contamination. Equal amounts of total RNA $(1 \mu \mathrm{g})$ were reverse transcribed into cDNA by the random hexamer method. cDNA was subsequently amplified by PCR in the presence of specific primers, according to the instructions provided by the manufacturer (GeneAmp RNA PCR Kit; Perkin-Elmer Cetus, Wellesley, MA). Primers, step cycles, and expected length of the amplification products used in this study are summarized in Table 1. Preliminary experiments demonstrated that these PCR conditions were within the linear range of amplification of gene fragments. Under the conditions reported in Table 1, PCR products separated on agarose and stained with ethidium bromide showed a major band of the predicted size (data not shown). During the PCR reaction, the nonradioactive label digoxigenin-11-dUTP (DIG; Roche Biochemimcals) was incorporated, and the DNA fragments separated by electrophoresis in agarose were blotted onto a nylon membrane for 16 hours in $10 \times$ SSC. The blot was exposed to x-ray film (X-OMAT; Eastman-Kodak, Rochester, NY) for 2 to 10 minutes in an $\mathrm{x}$-ray cassette at room temperature. The overall procedure was standardized by expressing the amount of PCR product for G6PD mRNA relative to the amount of product formed for $\beta$-actin. Image-analysis software (The National Institutes of Health Image 1.63; Scion Image, Frederick, MD) was used to assess the intensity of the bands in the autoradiograms.

\section{Autofluorescence Analysis}

Green autofluorescence in cells, caused by the formation of conjugated Schiff base compounds from aldehydes derived from lipid peroxidation and amino groups of phospholipids or cell proteins, has been proposed as an indicator of oxidative injury. ${ }^{29}$ Therefore, the green autofluorescence was investigated in single living fibroblasts grown under the conditions described earlier. The cells were viewed with an inverted microscope (IX 71; Olympus), equipped with $20 \times / 0.7$ or
$60 \times / 1.3$ planapochromatic objective (UPlanSApo series; Olympus). Images were captured by a digital camera and transferred to a personal computer to evaluate, by using the image-analysis software (NIH Image $J$ ), the intensity of green autofluorescence, which was expressed as number of pixels per cell.

\section{Cell Response to Oxidative Stress}

To evaluate acute response to oxidative stress, the four groups of fibroblasts were maintained and propagated in DMEM (supplemented with $10 \%$ fetal bovine serum (FCS; Roche Biochemicals) at $37^{\circ} \mathrm{C}$ in $5 \%$ $\mathrm{CO}_{2}$ humidified atmosphere. The cells were seeded in 96-well flatbottomed plates (Invitrogen) at a density of $1 \times 10^{4} /$ well, and allowed to settle overnight. Oxidative stress on the cells was delivered by exposing subconfluent cultures to 0.5 and $250 \mathrm{mM}$ concentrations of $\mathrm{H}_{2} \mathrm{O}_{2}$ in a phosphate-buffered saline (PBS) for 30 minutes at $37^{\circ} \mathrm{C}$. Thereafter, the oxidizing solution was removed from monolayers and, after two washings with warm PBS, replaced with growth medium. Cell response to oxidative stress was evaluated either immediately (30 minutes) and 24 hours after $\mathrm{H}_{2} \mathrm{O}_{2}$ treatment by determining cell viability with the MTT [3-(4,5-dimethylthiazol-2-yl)-2,5-diphenyltetrazolium bromide] method. ${ }^{30}$

\section{Statistical Analysis}

Data are reported as the mean \pm SE. Statistical comparisons between the four groups were made by one-way ANOVA and, when appropriate, a post hoc Bonferroni test. A probability of $P<0.05$ was considered statistically significant. For statistical evaluation of prevalence studies, the $\chi^{2}$ test was used (Origin; Microcal, Inc., Northampton, MA, and Statistica; StatSoft, Tulsa, OK).

\section{Results}

\section{Study Group}

The study group consisted of 123 patients with primary pterygium (99 men and 24 women; mean age $57.1 \pm 13.9$ and $58.0 \pm 15.4$ years, respectively) admitted for pterygium surgery at the University Eye Clinic of Cagliari (Sardinia), between January 2005 and June 2009. Similar to other studies, ${ }^{24-26}$ the control group was selected from patients undergoing cataract surgery ( 92 men; mean age, $59.0 \pm 10.7$ years and 20 women; mean age, $59.8 \pm 15.8$ years). A second control group of 8445 blood donors (6238 men and 2207 women aged between 18 and 65 years) surveyed in the same period at the Hospital Transfusion Center, Cagliari, was evaluated in G6PD prevalence studies.

All hemizygotic G6PD - men and all homozygotic G6PDwomen showed residual erythrocyte enzyme activity, ranging from 0 to $0.2 \mathrm{IU} / \mathrm{g}$ of $\mathrm{Hb}$. Heterozygotic G6PD - women showed residual erythrocyte enzyme activity, ranging from 2 to $10 \mathrm{IU} / \mathrm{g}$ of $\mathrm{Hb}$. Male and female subjects with residual erythrocyte enzyme activity higher than $10 \mathrm{IU} / \mathrm{g}$ of $\mathrm{Hb}$ were considered G6PD +. G6PD deficiency was found in 24 (24.2\%) of 99 male patients with pterygium, $11(12 \%)$ of 92 men with cataract, 11 (46\%) of 24 women with pterygium, and 2 (10\%) of 20 women with cataract (Table 2). The estimated relative risk (RR) of a G6PD - compared with a G6PD + for development of 
TABLE 2. Prevalence of G6PD - in Patients with Pterygium

\begin{tabular}{|c|c|c|c|c|c|c|}
\hline & \multicolumn{2}{|c|}{$\begin{array}{l}\text { Pterygium } \\
\text { Cases }\end{array}$} & \multicolumn{2}{|c|}{$\begin{array}{l}\text { Cataract } \\
\text { Controls }\end{array}$} & \multicolumn{2}{|c|}{$\begin{array}{l}\text { Blood Donor } \\
\text { Controls }\end{array}$} \\
\hline & $n$ & $\%$ & $n$ & $\%$ & $n$ & $\%$ \\
\hline \multicolumn{7}{|l|}{ Men* } \\
\hline Normal & 75 & 75.8 & 81 & 88.0 & 5482 & 81.9 \\
\hline G6PD - & 24 & 24.2 & 11 & 12.0 & 756 & 12.1 \\
\hline Total & 99 & 100 & 92 & 100 & 6238 & 100.0 \\
\hline \multicolumn{7}{|l|}{ Women $\dagger$} \\
\hline Normal & 13 & 54 & 18 & 90 & 1976 & 89.4 \\
\hline G6PD- & & & & & & \\
\hline $\begin{array}{l}\text { Severe } \\
\text { Intermediate }\end{array}$ & $11 \mathrm{~s}$ & 46 & $2 \delta$ & 10 & $\begin{array}{r}58 \neq \\
173 \rrbracket\end{array}$ & $\begin{array}{l}2.8 \\
7.8\end{array}$ \\
\hline Total & 24 & 100 & 20 & 100 & 2207 & 10.0 \\
\hline
\end{tabular}

${ }^{*} \chi^{2}$ pterygium cases vs. cataract controls, $P=0.045 ; \chi^{2}$ pterygium cases vs. blood donor controls, $P=0.000$.

$\dagger \chi^{2}$ pterygium cases vs. cataract controls, $P=0.024 ; \chi^{2}$ pterygium cases vs. blood donor controls, $P=0.000$.

‡ Severe G6PD deficiency.

$\S$ Intermediate G6PD deficiency.

pterygium was 2.45 (95\% CI, $1.37-4.39 ; P=0.0026)$. The frequency of G6PD deficiency $(12.1 \%$ in men and $10.6 \%$ in women) found in the blood donor group was comparable to that in the cataract population. ${ }^{31}$

To understand the biological significance, if any, of these epidemiologic studies, we next analyzed the correlation between G6PD activity, growth rate, and lipid metabolism in primary cultured fibroblasts isolated from normal human conjunctiva (NCFs) and pterygium (PFs), both G6PD+ and G6PD - . It is important to recall that G6PD deficiency is a sex-linked disorder; hence, the defect in affected men is fully expressed in all nucleated cells. The majority of G6PD - females, instead, have a mosaic pattern of affected cells, indicating the presence of a mixture of normal and deficient cell populations. Therefore, to avoid the risk of collecting G6PD+ fibroblasts from G6PD - women, only men were recruited for these experiments.

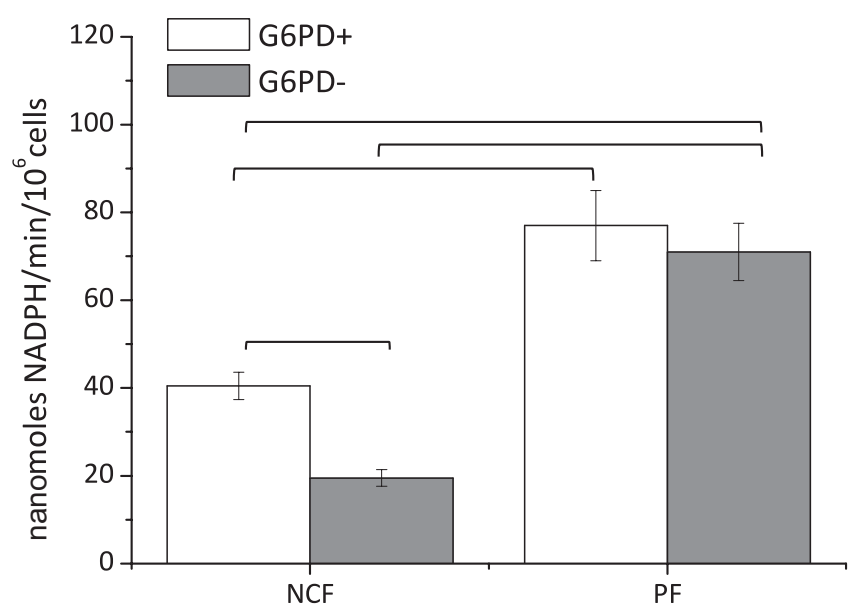

FigURE 1. G6PD activity in NCFs and PFs. Enzyme activity was measured in fibroblast homogenates and expressed in nanomoles NADPH formed per minute per $10^{6}$ cells. Data are the mean \pm SE of eight NFCs (four G6PD + and four G6PD-) and eight NFCs (four G6PD- and four G6PD +) measured in duplicate. Statistical analysis by one-way ANOVA showed significant differences between the groups $(P=0.000)$ and was followed by the Bonferroni multiple-comparison test $(P<0.05$ between the groups linked by square brackets).

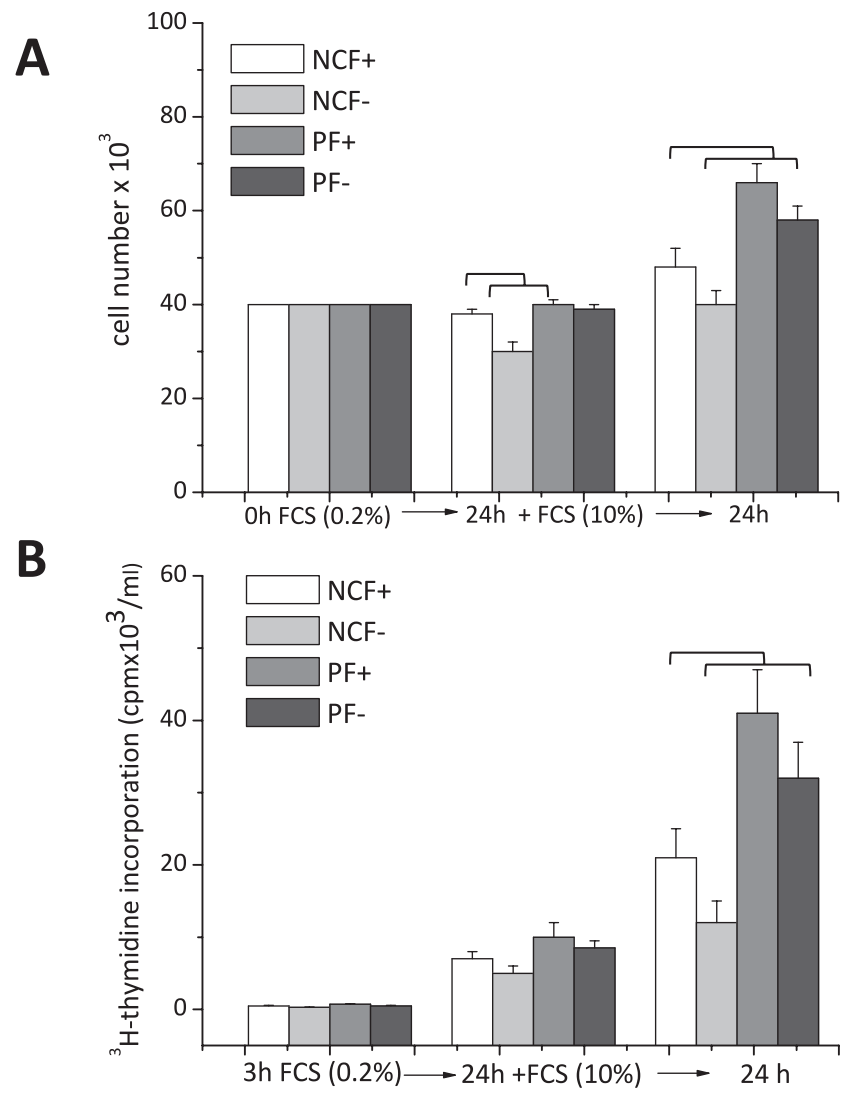

Figure 2. Growth rate in NCFs and PFs. For growth rate determination cells were placed at a density of 40,000 cell $/ \mathrm{cm}^{2}$ in six-well plates and then were incubated for 24 hours in DMEM with $0.2 \%$ FCS to synchronize cells at a quiescent state. Quiescent fibroblasts were then diluted in complete growth medium containing $10 \%$ fetal calf serum (FCS) and incubated for a further 24 hours. Data shown are the mean \pm SE of eight NFCs (four G6PD + and four G6PD-) and eight NFCs (four G6PD - and four G6PD+) made in duplicate. (A) Cell number as determined by hemocytometer. Statistical analysis performed by using the one-way ANOVA test showed highly significant differences between the groups $(P=0.000)$, followed by the Bonferroni multiplecomparison test $(P<0.05$ between the groups linked by square brackets). (B) ${ }^{3} \mathrm{H}$-Thymidine incorporated into DNA. ${ }^{3} \mathrm{H}$-Thymidine (10 $\mu \mathrm{Ci} / \mathrm{mL}$ ) was added three hours before harvesting cells. Statistical analyses and significance are as described in Figure 1.

\section{G6PD Activity in NCFs and PFs}

As shown in Figure 1, G6PD activity was significantly lower ( $\sim 45 \%$ less) in NCFs - compared with NCF + . However, no significant difference was observed between PF + and PFs-. Of interest, G6PD activity was significantly higher in the PFs, both G6PD + and G6PD - compared with the corresponding NCFs.

\section{Growth Analysis}

Growth rate was assessed by counting cells with a hemocytometer and by incorporating $\left[{ }^{3} \mathrm{H}\right]$ thymidine into DNA (Figs. $2 \mathrm{~A}, 2 \mathrm{~B}$, respectively). According to other studies that demonstrate that pterygial fibroblasts have acquired many of the properties of the transformed phenotype, ${ }^{32}$ PFs grow faster than NCFs. However, although NCFs- grow more slowly than NCFs,+ PFs - , and PFs + grow at the same rate.

It is well known that highly proliferating cells require large amounts of ribose for nucleic acid synthesis, raising the question of how $\mathrm{PF}-$ may grow at the same rate as $\mathrm{PF}+$. To try to 


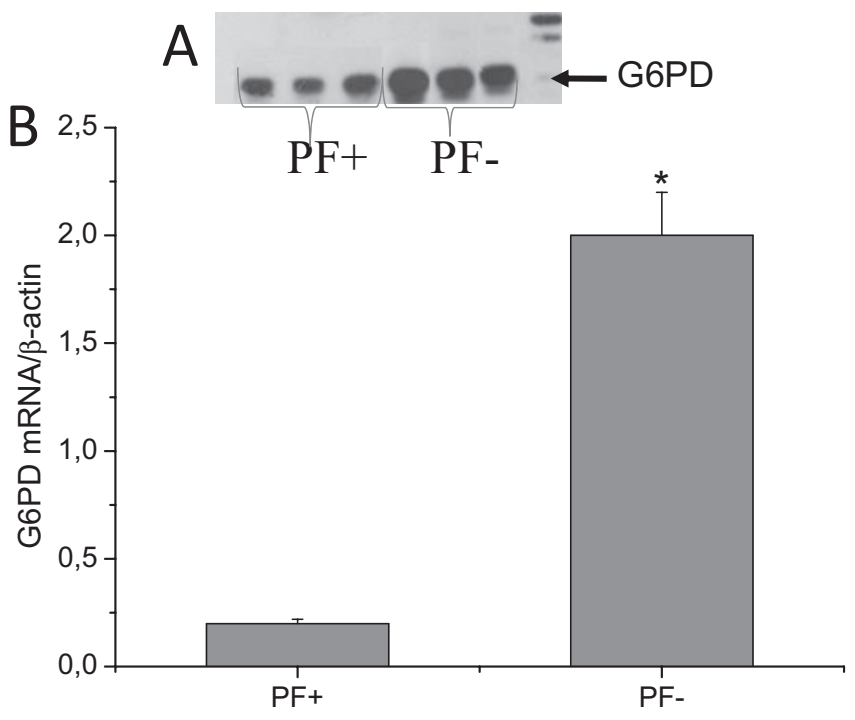

FiguRe 3. G6PD mRNA levels in PFs + and PFs-. Total mRNA was extracted from $10^{6}$ cells in the quiescent state. mRNA levels were determined by RT-PCR with the appropriate primer sets. Specific bands were detected after addition of a chemiluminescent substrate and analyzed with image-analysis software. (A) Representative blots of G6PD in three PF + and three PF - cultures. (B) Densitometric analysis of mRNA levels, normalized for the endogenous $\beta$-actin mRNA. Data values are represented as mean $\pm \mathrm{SE}^{*} P<0.05$ versus $\mathrm{PF}+$.

answer this question, we determined the levels of G6PD mRNA in $\mathrm{PF}+$ and $\mathrm{PF}-$. As shown in Figure 3 we found that mRNA levels of G6PD in the PF- cells were significantly higher than those in the $\mathrm{PF}+$ cells.

\section{Autofluorescence in NCFs and PFs}

Given the role of G6PD in cellular redox homeostasis maintenance and considering that oxidative stress induced by UV represents the main cause of pterygium, another important point to investigate was oxidative injury in NCFs $(+/-)$ and in PFs $(+/-)$. Since green autofluorescence in cells, caused by the formation of conjugated Schiff base compounds from aldehydes derived from lipid peroxidation and amino groups of phospholipids or cell proteins, has been proposed as an indicator of oxidative injury, ${ }^{29}$ we determined green autofluorescence in the cells. Representative green autofluorescence images of NCFs $(+/-)$ and PFs $(+/-)$, recorded under a $535-\mathrm{nm}$ emission signal, are shown in Figure 4A. As expected, at 0 hours and at 24 hours, green autofluorescence was higher in NCFs - than in NCFs + . Despite the high G6PD activity, PF $(+/-)$ exhibited higher green autofluorescence than the corresponding NFCs $(+/-)$ (Fig. $4 \mathrm{~B})$.

\section{Cell Response to Oxidative Stress}

To reinforce this result, we exposed the four groups of fibroblasts to oxidative stress produced by a pro-oxidant agent, hydrogen peroxide $\left(\mathrm{H}_{2} \mathrm{O}_{2}\right)$ in two different concentrations $(0.5$ and $250 \mathrm{mM}$ ). As shown (Fig. 5A), soon after stress application (30 minutes), the cell mass of $\mathrm{H}_{2} \mathrm{O}_{2}$-treated $\mathrm{NFC}+$ was comparable to that of unstressed cells, and a slight but nonsignificant decrease in cell mass was seen 24 hours after $\mathrm{H}_{2} \mathrm{O}_{2}$ treatment. On the other hand, as early as 30 minutes after oxidative stress, the cell mass of $\mathrm{NCF}-, \mathrm{PF}+$, and $\mathrm{PF}-$ significantly decreased (Fig. 5B) and decreased further after 24 hours.

\section{Determination of Neutral Lipids in NCFs and PFs}

In an earlier paper we demonstrated that intracellular lipid accumulation, mainly cholesterol esters (CEs), represent an
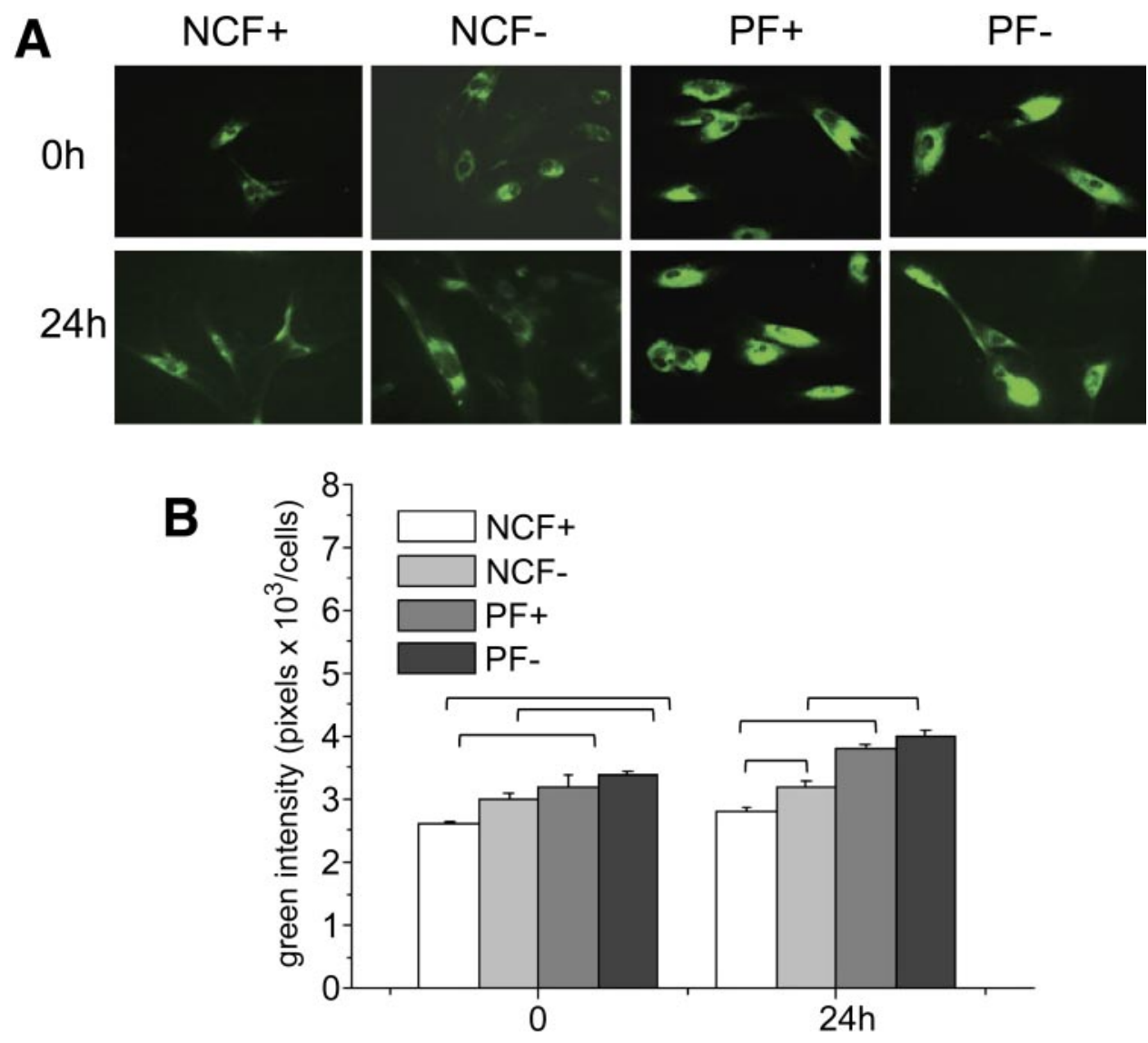

FIGURE 4. Green autofluorescence in NCFs and PFs. (A) Examples of green autofluorescence in NCFs and PFs. (B) Quantitative analysis of green autofluorescence intensities. Data are expressed as the mean \pm SE from four samples for each group, made in duplicate. At least 50 cells were measured for each sample. Statistical analyses and significance are as described in Figure 1. 


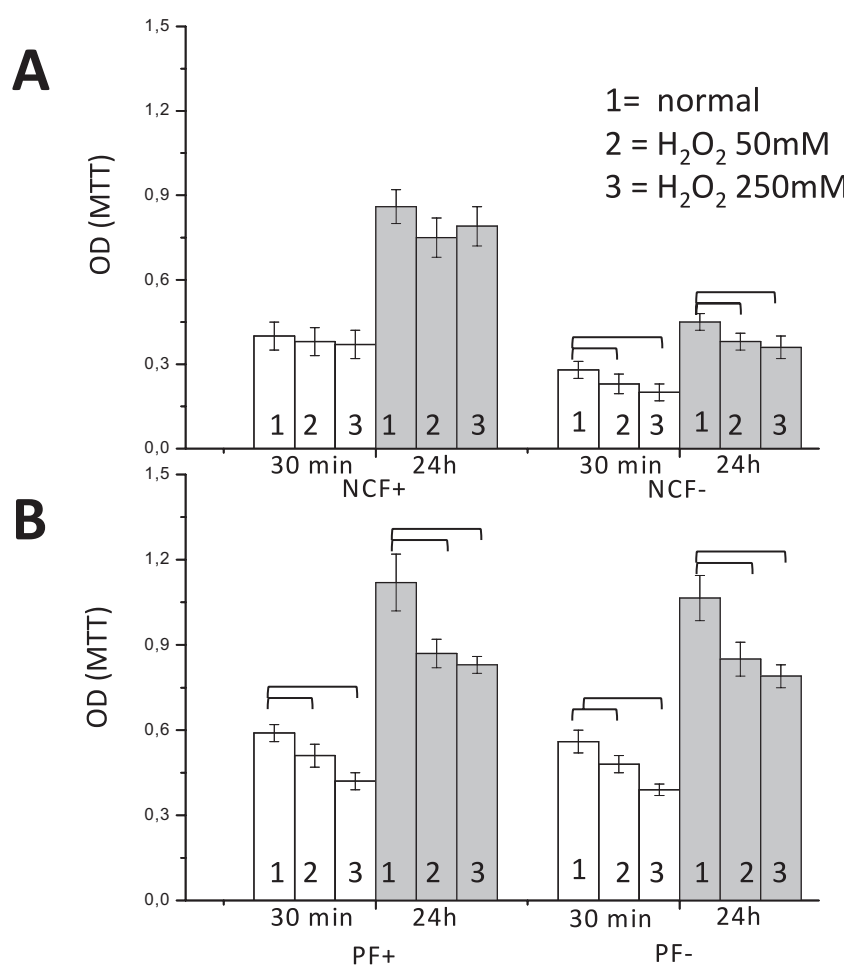

Figure 5. Cell response to oxidative stress. Normal and pterygium fibroblasts were maintained and propagated in D-MEM supplemented with $10 \%$ FCS. The Cells were seeded in 96-well flat-bottomed plates at a density of $1 \times 10^{4} /$ well and allowed to settle overnight. Oxidative stress to cells was delivered by exposing subconfluent cultures to two concentrations $(0.5$ and $250 \mathrm{mM})$ of $\mathrm{H}_{2} \mathrm{O}_{2}$ in PBS for 30 minutes at $37^{\circ} \mathrm{C}$. Thereafter, the oxidizing solution was removed from monolayers and replaced with growth medium. Cell response to oxidative stress was evaluated either immediately (time 30 minutes) and 24 hours after $\mathrm{H}_{2} \mathrm{O}_{2}$ treatment by determining cell viability with the MTT method. (A) Cell mass of NCF $(+/-)$ as determined by MTT test. (B) Cell mass of PF $(+/-)$ as determined by MTT test. For both cell types, data are represented as the mean $\pm \mathrm{SE}$ of result in four samples from each group, made in duplicate. Statistical analyses and significance are as described in Figure 1.

important element in the control of cell proliferation during pterygium progression. ${ }^{24-26}$ In accordance with this finding, at time 0 , PFs accumulated more neutral lipids than did the NCFs, as determined by directly staining the cytoplasmic neutral lipids with ORO (Fig. 6). At 24 hours, cytoplasmic ORO staining became markedly apparent in $\mathrm{NCF}+, \mathrm{PF}+$, and $\mathrm{PF}-$, but not in NCF- cells, indicating that lipid accumulation positively correlates with cell growth rate.

\section{Nile Red and Filipin Staining of NCFs and PFs}

NCFs and PFs from G6PD + and G6PD - subjects were also stained with Nile red to detect polar (i.e., membrane phospholipids, PL) and neutral lipids (i.e., CE), based on the different sensitivities of red (NR-590) and yellow (NR-535) Nile red emissions for weakly and highly hydrophobic lipids, respectively. Nile red was used in combination with filipin to colocalize free cholesterol (FC). In agreement with ORO data, at 0 hours, $\mathrm{PF}+$ and $\mathrm{PF}-$ showed a higher (NR-535) signal, indicative of higher concentrations of neutral lipids. Neutral lipids were significantly higher in NCFs+ compared with NCFs - at the two time points considered. A significantly higher NR-590 signal and more intense filipin staining were observed in PFs (data not shown). Taken together, these data further support the concept that neutral lipid, rather than other polar lipids (i.e., FC and PL) play an essential part in cell proliferation control. Representative images and quantitative data are shown in Figures $7 \mathrm{~A}$ and $7 \mathrm{~B}$, respectively.

\section{Discussion}

The high prevalence of G6PD deficiency found in patients affected by primary pterygium, both men and women, suggests that this enzymatic defect is a predisposing factor for pterygium development. Considering the role of G6PD in cellular growth $^{13,14}$ and the proliferative nature of pterygium, ${ }^{24-26,32}$ this finding was surprising. However, although NCF- residual G6PD activity was approximately $45 \%$ of that in NCFs + , in PFs - residual enzymatic activity was approximately $95 \%$ of that in PFs + . Moreover, in PFs-, G6PD mRNA levels were significantly higher than in PFs + , indicating that, under conditions of increased demand, such as during active cell proliferation, G6PD - nucleated cells compensate for the very rapid decay of their mutated enzyme, by producing more enzyme molecules. Supporting this, PFs grew at a faster rate than NCFs, and, although NCFs - grew more slowly than NCFs + , PFsand PFs + had the same rate of growth. Given that pterygium fibroblasts resemble a tumorigenic phenotype ${ }^{24-26,32}$ the results of the present study match well with those of earlier papers of ours that described higher G6PD activity and mRNA levels in G6PD - leukemic cells compared with deficient peripheral blood mononuclear cells, as well as in G6PD - tumoral lung tissue compared with surrounding nontumoral tissue. ${ }^{13,14}$ In addition, they are in agreement with results obtained by other investigators ${ }^{33}$ who demonstrated that in normal cells, G6PD expression is tightly controlled, although in many tumors, regulation of its expression is altered, resulting in a significant increase in G6PD activity.

ROS and metabolic activation have been known to modulate gene expression, and several studies have confirmed the role of oxidative stress in tumor formation. ${ }^{34-36}$ Oxidative stress occurs when ROS production overrides the antioxidant capability (mainly represented by GSH) of the target cell; oxidative damage caused by the interaction of reactive oxygen with critical cellular macromolecules can occur. ROS interact with, and modify, cellular proteins, lipids, and DNA, resulting in altered target-cell function. The accumulation of oxidative damage has been implicated in both acute and chronic cell injury, including possible involvement in cancer formation. ${ }^{34-36}$ It has been suggested that acute oxidative stress causes selective cell death and hence a temporary blockage of cell growth, ${ }^{36,37}$ followed by a compensatory increase in cell proliferation, which may favor selective clonal expansion of any latent initiated preneoplastic cells. On the other hand, oxidative stress of a sublethal chronic kind, by causing unrepaired DNA injury, can produce latent preneoplastic cells that are at risk of becoming tumoral if growth stimulated. ${ }^{38}$

Our finding of increased green autofluorescence in ex vivo $\mathrm{NCF}-$ compared with NCFs + is indicative of an accumulation of oxidative damage in nontumoral G6PD - deficient cells. This evidence suggests that these cells, being more sensitive to oxidative stress, probably due to their inability to maintain GSH at normal levels, are at high risk of being transformed. Supporting this notion, after acute (30 minutes) exposure to oxidative stress produced by a pro-oxidant agent, $\mathrm{H}_{2} \mathrm{O}_{2}$, greater toxicity was observed in NCFs- compared with NCFs+.

However, more intense green autofluorescence coupled with greater cell toxicity caused by acute $\mathrm{H}_{2} \mathrm{O}_{2}$ exposure was found in both PFs + and PFs - , compared with corresponding $\mathrm{NCF}$, raising the question of why PFs $(+/-)$, which have high G6PD activity and, hence, an expected abundance of GSH-, are more sensitive to oxidative stress. 
$\mathrm{NCF}+$

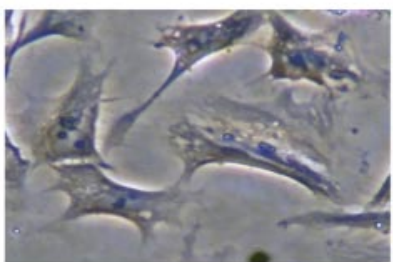

$\mathrm{Oh}$

$24 \mathrm{~h}$

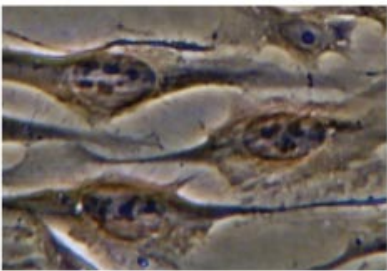

NCF-
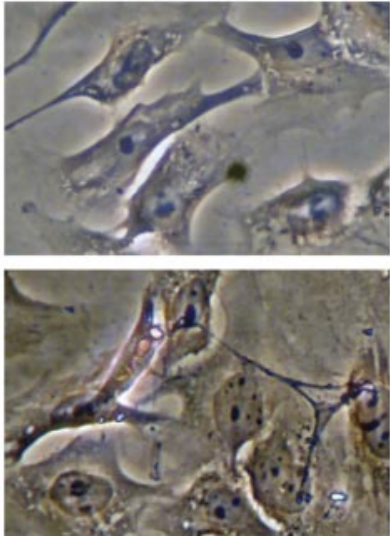

PF+
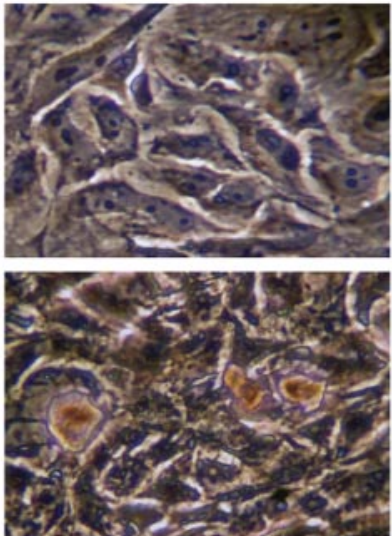

PF-
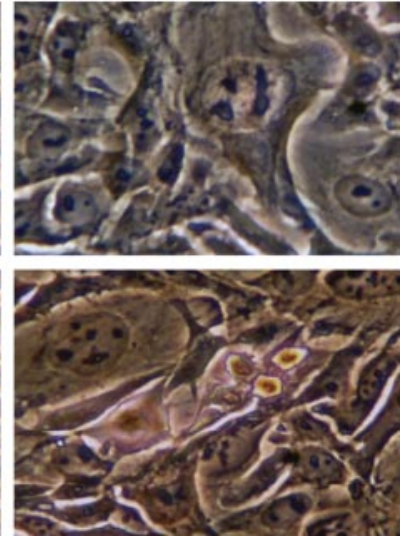

FigURE 6. ORO staining of NFCs and PFs. For this experiment, fibroblasts between passages 2 and 4 of culture were plated at a density of 10,000 cell $/ \mathrm{cm}^{2}$ and then incubated for 24 hours in DMEM with $0.2 \%$ FCS to synchronize cells in a quiescent state. Quiescent fibroblasts $(0$ hours) were then diluted in complete growth medium with $10 \%$ FCS and incubated for a further 24 hours. Representative microscopic visualization of neutral lipid accumulation in two NFC (one + and one - ), and 2 PF (one + and one - ) cell cultures. The cells were treated with isopropyl alcohol (60\%), washed, stained with ORO, and counterstained with Mayer's hematoxylin. The stained cells were examined by light microscopy, and digital images were recorded.

In the present study, we found that ex vivo PFs accumulated more neutral lipids than did NCFs. After 24 hours of FCS growth stimulation, neutral lipids markedly increased in $\mathrm{NCFs}+, \mathrm{PFs}+$, and $\mathrm{PFs}-$, but not in NCFs - . In addition, PFs $(+/-)$, stained with Nile red to detect polar $(\mathrm{PL})$ and neutral lipids (i.e., TG and $\mathrm{CE}$ ), in combination with filipin to colocalize FC, showed not only higher neutral lipid levels than did NCFs $(+/-)$, but also increased levels of PL and FC.
These results, besides confirming that lipid accumulation positively correlates with cell growth rate, lead us to speculate that the maintenance of lipid homeostasis is an essential mechanism in normal cell proliferation control. NADPH is a highenergy molecule used for anabolic pathways, such as lipid synthesis, cholesterol synthesis, and fatty acid chain elongation, all of which were found to be increased in PFs. It is therefore possible to hypothesize that increased NADPH de-
A

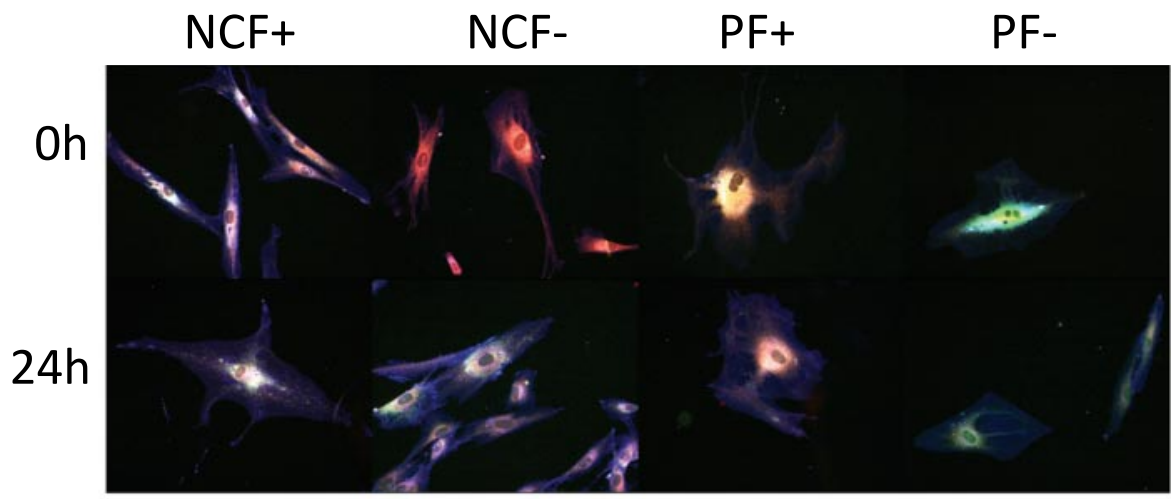

B

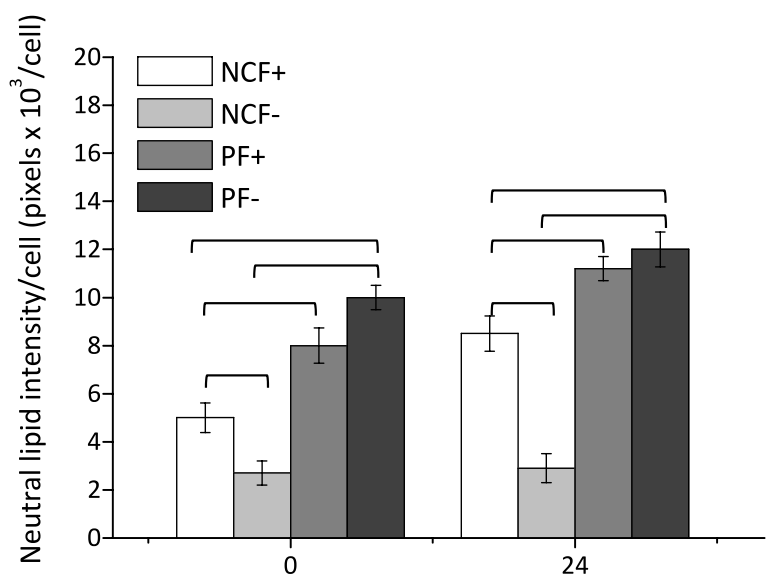

hours after FCS stimulation
FigURE 7. Nile Red and filipin staining of NCFs and PFs. (A) Representative images of fibroblasts stained with Nile red (NR) and filipin. Nile red emissions (NR-590) distinguished weakly hydrophobic (i.e., phospholipids) from highly hydrophobic (i.e., triglycerides and cholesterol ester) lipids (Nile yellow emissions, NR-535). Filipin stained free cholesterol. (B) Quantitative analysis of NR-535 staining. Plots show the mean $\pm \mathrm{SE}$ of the intensity of NR-535-stained fibroblasts. Data were obtained from six microscopic fields per group, each field including a total area of $325 \mu \mathrm{m}^{2}$ of cytoplasm (excluding the background). Statistical analyses and significance are as described in Figure 1. 
mand for lipid synthesis, which is essential for the maintenance of cell growth, drastically reduces the availability of NADPH for GSH regeneration. This may expose the cells to a higher risk of oxidative damage and the mentioned consequences.

In conclusion, the results of this study, although restricted to a limited group of subjects (i.e., those of Sardinian ancestry), suggest that, despite what might be argued, G6PD deficiency not only does not protect against pterygium, but may even be considered a risk factor for the development of this disorder.

\section{Acknowledgments}

The authors thank Anna Saba for technical assistance, Edward Steeden for revision of the English, and Rosa Manconi and Michele Bajorek for providing the blood donors for epidemiologic study.

\section{References}

1. Beutler E. Glucose 6-phosphate dehydrogenase. In: Stanbury JB, Wyngaarden JB, Fredrickson DJ, Goldstein JL, Brown MS, eds. The Metabolic Basis of Inherited Disease. NewYork: McGraw-Hill; 1983;1629-1653.

2. Kruger NJ, von Schaewen A. The oxidative pentose phosphate pathway: structure and organisation. Curr Opin Plant Biol. 2003; 6(3):236-246.

3. Burak Cimen MY. Free radical metabolism in human erythrocytes. Clin Chim Acta. 2008;390:1-11.

4. Fico A, Paglialunga F, Cigliano L, et al. Glucose-6-phosphate dehydrogenase plays a crucial role in the protection from redox-stress induced apoptosis. Cell Death Differ. 2004;11:823-831.

5. Veech RL. A humble hexose monophosphate pathway metabolite regulates short- and long-term control of lipogenesis Proc Natl Acad Sci USA. 2003;100(10):5578-5580.

6. Eigenbrodt E, Reinacher M, Scheefers-Borchel U, Scheefers H, Friis R. Double role for pyruvate kinase type M2 in the expansion of phosphometabolite pools found in tumor cells. Crit Rev Oncog. 1992;3:91-115.

7. Luzzatto L, Battistuzzi G. Glucose-6-phosphate dehydrogenase variants. Adv Hum Genet. 1985;14:217-329.

8. Fenu MP, Finazzi G, Manoussakis C, Palomba V, Fiorelli G. Glucose6-phosphate dehydrogenase deficiency: genetic heterogeneity in Sardinia. Ann Hum Genet. 1982;46:105-114.

9. Luzzatto L, Mehta A, Vulliamy T. Glucose-6-phosphate dehydrogenase deficiency. In: Scriver CR, Beaudet AL, Sly WS, eds. The Metabolic Basis of Inherited Disease. Vol 3. New York: McGrawHill; 2001;4517-4553.

10. De Vita G, Alcalay M, Sampietro M. Cappelini D, Fiorelli G, Toniolo D. Two point mutations are responsible for G6PD polymorphism in Sardinia. Am J Hum Genet. 1989;44:233-240.

11. Huang Y, Choi MY, Au Ngor Wing S, et al. Purification and detailed study of two clinically different human glucose 6-phosphate dehydrogenase variants, G6PDPlymouth and G6PDMahidol: evidence for defective protein folding as the basis of disease. Mol Genet Metab. 2008;93:44-53.

12. Keller DF, Kellermeyer RW. Erythrocyte glucose-6-phosphate dehydrogenase deficiency a pharmacogenetic prototype. Crit Rev Clin Lab Sci. 1970;1:247-302.

13. Dessì S, Batetta B, Cherchi R, Onnis R, Pisano M, Pani P. Hexose monophosphate shunt enzymes in lung tumors from normal and glucose-6-phosphate-dehydrogenase-deficient subjects. Oncology. 1988; 45:287-291.

14. Batetta B, Pulisci D, Bonatesta RR, et al. G6PD activity and gene expression in leukemic cells from G6PD-deficient subjects. Cancer Lett. 1999;140:53-58.

15. Sulis E. G-6-PD deficiency and cancer. Lancet. 1972;1(7761):1185.
16. Meloni L, Manca MR, Loddo I, et al. Glucose-6-phosphate dehydrogenase deficiency protects against coronary heart disease. J Inberit Metab Dis. 2008;31:412-417.

17. Forteleoni G, Argiolas L, Farris A, Ferraris AM, Gaetani GF, Meloni T. G6PD deficiency and breast cancer. Tumori. 1988;74:665-667.

18. Cocco P, Dessí S, Avataneo G, Picchiri G, Heinemann E. Glucose6-phosphate dehydrogenase deficiency and cancer in a Sardinian male population: a case-control study. Carcinogenesis. 1989;10: 813-816.

19. Cocco P, Todde P, Fornera S, Manca MB, Manca P, Sias AR. Mortality in a cohort of men expressing the glucose-6-phosphate dehydrogenase deficiency. Blood. 1998;91:706-709.

20. Coroneo MT, Di Girolamo N, Wakefield D. The pathogenesis of pterygia. Curr Opin Ophthalmol. 1999;10:282-288.

21. Threlfall TJ, English DR. Sun exposure and pterygium of the eye: a dose-response curve. Am J Ophthalmol. 1999;128:280-287.

22. Dushku N, John MK, Schultz GS, Reid TW. Pterygia pathogenesis. Arch Ophthalmol. 2001;119:695-706.

23. Cheng ML, Ho HY, Wu YH, Chiu DT. Glucose-6-phosphate dehydrogenase-deficient cells show an increased propensity for oxidant-induced senescence. Free Radic Biol Med. 2004;36(5):580 591.

24. Peiretti E, Dessì S, Mulas MF, Abete C, Galantuomo MS, Fossarello M. Fibroblasts isolated from human pterygia exhibit altered lipid metabolism characteristics. Exp Eye Res. 2006;83:536-542.

25. Peiretti E, Dessì S, Mulas C, et al. Modulation of cholesterol homeostasis by antiproliferative drugs in human pterygium fibroblasts. Invest Ophthalmol Vis Sci. 2007;48:3450-3458.

26. Peiretti E, Dessì S, Putzolu M, Fossarello M. Hyperexpression of low-density lipoprotein receptors and hydroxy-methylglutaryl-coenzyme A-reductase in human pinguecula and primary pterygium. Invest Ophthalmol Vis Sci. 2004;45:3982-3985.

27. Beutler E. Red Cell Metabolism Manual of Biochemical Methods. London: Academic Press; 1971;68-70.

28. Diaz G, Batetta B, Sanna F, et al. Lipid droplet changes in proliferating and quiescent 3T3 fibroblasts. Histochem Cell Biol. 2008; 129:611-621.

29. Bidlack WR, Tappel AL. Fluorescent products of phospholipids during lipid peroxidation. Lipids. 1973;8:203-207.

30. Mosmann T. Rapid colorimetric assay for cellular growth and survival: application to proliferation and cytotoxicity assays. $\mathrm{J} \mathrm{Im}$ munol Methods. 1983;65:55-63.

31. Orzalesi N, Fossarello M, Sorcinelli R, Schlich U. The relationship between glucose-6-phosphate deficiency and cataracts in Sardinia: an epidemiologic and biochemical study. Doc Ophthalmol. 1984; 57:187-201.

32. Chen J-K, Tsai RJF, Lin S-S. Fibroblasts isolated from human pterygia exhibit transformed cell characteristics. In Vitro Cell Dev Biol. 1994;30:243-248.

33. Kuo W, Lin J, Tang TK. Human glucose-6-phosphate dehydrogenase (G6PD) gene transforms NIH 3 T3 cells and induces tumors in nude mice. Int J Cancer. 2000;85(6):857-864.

34. Armstrong JS, Steinauer KK, Hornung B, et al. Role of glutathione depletion and reactive oxygen species generation in apoptotic signaling in a human B lymphoma cell line. Cell Death Differ. 2002;9:252-263.

35. Martini G, Ursini MV. A new lease of life for an old enzyme. Bioessays. 1996;18:631-637.

36. Okada F. Beyond foreign-body-induced carcinogenesis: impact of reactive oxygen species derived from inflammatory cells in tumorigenic conversion and tumor progression. Int J Cancer. 2007;121: 2364-2372.

37. Yoon SO, Chang HY, Chung AS. Dose effect of oxidative stress on signal transduction in aging. Mech Ageing Dev. 2002;123:15971604 .

38. Trosko JE, Chang CC. Hallmarks of radiation carcinogenesis: ignored concepts. International Congress Series. 2003;1258:31-36. 